\title{
Sensitivity of Nonexposed and Exposed Populations of Magnaporthe oryzae from Rice to Tricyclazole and Azoxystrobin
}

Andrea Kunova, Cristina Pizzatti, Maria Bonaldi, and Paolo Cortesi, Università degli Studi di Milano, Department of Food, Environmental and Nutritional Sciences, 20133 Milano, Italy

\begin{abstract}
Kunova, A., Pizzatti, C., Bonaldi, M., and Cortesi, P. 2014. Sensitivity of nonexposed and exposed populations of Magnaporthe oryzae from rice to tricyclazole and azoxystrobin. Plant Dis. 98:512-518.

Magnaporthe oryzae is the major pathogen of cultivated rice worldwide, which can cause substantial losses to rice production. Rice blast management is based predominantly on the application of fungicides; however, only a little is known about responses of pathogen populations to the most widely used fungicides. In this work, the baseline sensitivity of the Italian $M$. oryzae population to tricyclazole and azoxystrobin in terms of mycelium growth was determined, and the possible adaptation of the pathogen population after several years of repeated exposure to fungicide treatments was evaluated. All the analyzed strains demonstrated higher sensitivity and variability to azoxystrobin (concentration of fungicide causing 50\% growth inhibi-

tion $\left.\left[\mathrm{ED}_{50}\right]=0.063 \mathrm{mg} \mathrm{liter}^{-1}\right)$ than to tricyclazole $\left(99.289 \mathrm{mg} \mathrm{liter}^{-1}\right)$ After comparing two additional populations collected from fields repeatedly treated with fungicides to the baseline, no decrease in sensitivity toward these fungicides was observed and no resistant strains were detected. The shift of the pathogen sensitivity toward these fungicides has not occurred, although we observed slightly increased variance associated with $\mathrm{ED}_{50}$ of azoxystrobin. Therefore, both azoxystrobin and tricyclazole can be used to manage rice blast in Italy but it will be important to continue monitoring $M$. oryzae population to early detect possible azoxystrobin resistance.
\end{abstract}

Rice (Oryza sativa L.), is one of the main staple crops cultivated worldwide. Although it is predominantly grown in Asia, it has been cultivated also in Europe since the 15th century. Italy is currently the main rice producer in the European Union, with a cultivation area of approximately 250,000 ha and a production of 1.5 million $t$, representing approximately $35 \%$ of the whole European Union rice production (16).

Magnaporthe oryzae B.C. Couch sp. nov. is the causal agent of rice blast disease, one of the most widespread and destructive diseases of rice worldwide (27). In Italy, it was described for the first time by Astolfi in 1828 and, since then, blast epidemics are recurring with increasing frequency and severity $(2,12)$. The fungus can overwinter in straw or other rice residues or, in areas characterized by cold winters, in infected rice seed, which serve as primary inoculum for disease epidemics $(11,19,28)$. M. oryzae can infect rice at all developmental stages, causing leaf or collar blast, and, more economically important, neck or panicle blast. Depending on the environmental conditions combined with the use of susceptible varieties, increasing nitrogen fertilization, and late buried sowing, rice blast can cause significant damage to rice, from $10 \%$ to almost $100 \%$ yield loss $(6,7)$. Therefore, the cultivation of resistant varieties and the use of fungicides play an important role in rice blast management. In Italy, almost 200 rice varieties are registered, most of which have intermediate to high susceptibility to rice blast (14). Hence, the application of fungicides remains the only effective way to manage rice blast epidemics (15).

Fungicides with diverse modes of action have been developed for rice blast management but, in Italy, two classes are mostly used: DHN-melanin biosynthesis inhibitors (MBIs) and quinone outside inhibitors (QoIs). MBIs are important and widely used; they do not interfere with the viability of $M$. oryzae directly but specifically inhibit the pathogen penetration into the host plant (10)

Corresponding author: P. Cortesi, E-mail: paolo.cortesi@unimi.it

Accepted for publication 11 October 2013.

http://dx.doi.org/10.1094/PDIS-04-13-0432-RE

(c) 2014 The American Phytopathological Society and reduce inoculum production and its virulence $(25,39)$. They can be divided into two subgroups based on the step in melanin biosynthesis pathway they target, either dehydration (MBI-D) or reduction (MBI-R) (9,26). MBI-D fungicides target scytalone dehydratase $(\mathrm{SDH})$ and include formulations such as carpropamid, dichlocymet, or fenoxanil $(26,35)$. Low risk of resistance development was expected for these fungicides (33); however, shortly after their introduction in use, MBI-D resistant strains emerged due to a single point mutation in the SDH gene $(23,36,42)$. In Asia, where MBI-D fungicides were used from 1998 and discontinued after the emergence of resistance, the proportion of the MBI-D-resistant subpopulation was quickly reduced, which may enable their reintroduction in practice in the future (35). On the other hand, MBI-R fungicides target two hydroxynaphthalene reductases involved in melanin biosynthesis and comprise compounds such as tricyclazole, pyroquilon, or phtalide $(21,26,37,38)$. Surprisingly, even after 30 years of their use in some countries, no resistance has been observed in the field $(26,34)$. Only several low-level tricyclazoleresistant strains of $M$. oryzae were obtained in laboratory conditions, all of which showed decreased fitness and reduced sporulation and pathogenicity to rice (44).

QoIs represent a group of mitochondrial respiration inhibitors derived from naturally occurring strobilurins, and include molecules such as azoxystrobin, kresoxim-methyl, trifloxystrobin, and so on. They negatively influence mycelium growth, sporulation, and spore germination of several fungi $(22,25)$. Specifically, they inhibit mitochondrial respiration by blocking the electron transfer at the Qo site of the cytochrome $b c_{1}$ complex in the inner mitochondrial membrane, thereby preventing the ATP formation and disrupting the energy cycle of the fungus (8). Similarly to MBI-D fungicides, diverse pathogens resistant to QoIs have been detected shortly after their introduction, including $M$. oryzae from rice and the closely related $M$. oryzae pathogenic to turfgrass, goosegrass, and barley $(4,21,40)$. These strobilurinresistant strains tolerated higher doses of these fungicides due to three different amino acid substitutions detected in the cytochrome $b$ target site (24).

For the durable management of rice blast, detailed and accurate information about the sensitivity of $M$. oryzae populations to fungicides in use and monitoring for fungicide-resistant strains are 
needed, particularly for molecules at risk of resistance applied repeatedly over many years.

In Italy, tricyclazole- and azoxystrobin-based fungicides were registered at the end of 1990 s and have been widely used for rice blast management since then. At present, approximately $75 \%$ of Italian rice-growing area is routinely treated with these fungicides one or two times per year, depending on cultivar susceptibility and risk of disease epidemics. Tricyclazole alone $\left(600 \mathrm{~g} \mathrm{ha}^{-1}\right)$ and axozystrobin alone $\left(1\right.$ liter ha $\left.\mathrm{h}^{-1}\right)$ are applied on approximately 50 and $7 \%$ of fungicide-treated area, respectively (13). Another $25 \%$ is treated with tricyclazole and azoxystrobin applied as tank mix, to widen the spectrum of activity of the mixture; azoxystrobin is usually added at $80 \%$ of the recommended application rate.

The current changes in European legislation concerning fungicide use resulted in withdrawal of tricyclazole from the market but the molecule is currently under evaluation for a new registration. Meanwhile, in Italy, due to the importance of this fungicide for rice blast management, it is being used under temporary permission.

The recent emergence of $M$. oryzae-resistant strains to axozystrobin in Japan (18) and the finding of reduced efficacy of tricyclazole in China (43) inspired us to hypothesize a possible shift of the sensitivity of the Italian population of M. oryzae. To test our hypothesis, we determined baseline responses of the pathogen to both fungicides in terms of mycelium growth, using nonexposed strains collected from Italian rice fields in the 1990s, before tricyclazole- and azoxystrobin-based fungicides were marketed. Dose-response curves calculated from the baseline data were compared with those obtained for (i) populations collected 12 years later from rice fields repeatedly treated with fungicides and (ii) populations obtained under experimental fungicides selection.

\section{Materials and Methods}

Materials. Strains of M. oryzae were collected from Italian rice fields from the most important rice-growing provinces: Milano, Novara, Pavia, and Vercelli (Table 1). Diseased tissues were incubated for 1 to 2 days in a moist chamber to promote pathogen sporulation. Spores were collected with the aid of a sterile brush and spread on malt-extract agar medium (MEA; malt extract at $20 \mathrm{~g}$ liter $^{-1}$ and bacteriological agar number 1 at $15 \mathrm{~g} \mathrm{liter}^{-1}$; Oxoid Ltd.) to obtain single-spore isolates.

Strains of the 1998 population were collected from fields that had not been previously exposed to fungicide treatments in two different localities in Pavia and Novara provinces. Isolates of the 2010 population were collected in Pavia province from fields that have been regularly treated since the 1990s with tricyclazole (one to two times per year) or with a tank-mix of tricyclazole and azoxystrobin.

Finally, the 2011 population consisted of strains collected in fields of 15 localities of the four provinces that have been annually and repeatedly treated with tricyclazole and azoxystrobin since the 1990s. In this case, after the incubation of diseased tissues in a moist chamber to promote sporulation, the spores were spread on three different media to obtain three subpopulations: the control medium (MEA without fungicide supplement) to obtain strains of the control group (2011-control), MEA supplemented with tricyclazole at $200 \mathrm{mg} \mathrm{liter}^{-1}$ (2011T-selected), or MEA supplemented with azoxystrobin at $1 \mathrm{mg} \mathrm{liter}^{-1}$ (2011A-selected), concentrations approximately equal to the concentration of fungicide causing $90 \%$ growth inhibition $\left(\mathrm{ED}_{90}\right)$ and $75 \%$ growth inhibition, respectively.
The commercial formulations of fungicides tricyclazole (Beam WP; wettable powder, $75 \%$ a.i., registration number 9663 04/06/1998) and azoxystrobin (Amistar SC; suspension concentrate, $22.9 \%$ a.i., registration number 10118 30/07/1999), used in all experiments, were from Dow Agrosciences Italia and Syngenta Crop Protection, respectively.

Mycelium growth on media supplemented with fungicides. The activity of tricyclazole and azoxystrobin on mycelium growth of $M$. oryzae strains was evaluated as described previously (25). Specifically, the stains were grown on MEA medium supplemented with increasing concentrations of the two fungicides, added after sterilization: $0,0.001,0.01,0.1,1,10$, 33.3 , and $100 \mathrm{mg} \mathrm{liter}^{-1}$ for azoxystrobin and $0,0.01,0.1,1,10$, $33.3,66.65,100,216.65$, and $333.3 \mathrm{mg} \mathrm{liter}^{-1}$ for tricyclazole. A mycelium plug $(0.5 \mathrm{~cm}$ in diameter) obtained from a 10-day-old culture was transferred to MEA with or without fungicide in five replicates. The plates were then incubated at $26^{\circ} \mathrm{C}$ in the dark. Mycelium growth, expressed as colony diameter minus $0.5 \mathrm{~cm}$ (the diameter of the initial mycelium plug), was measured after 7 days of incubation.

Mycelium growth on salicylhydroxamic-acid-supplemented media. Many fungal species encode alternative oxidase (AOX) involved in electron transport, which can partially rescue the action of QoI inhibitors; therefore, activity of strobilurins is often evaluated in the presence of the AOX inhibitor, salicylhydroxamic acid (SHAM; 3,5,20,22). M. oryzae is known to encode AOX (5); however, SHAM has a minimal effect on concentration of fungicide (axozystrobin) causing 50\% growth inhibition $\left(\mathrm{ED}_{50}\right)$ of $M$. oryzae mycelium compared with other species such as Botrytis cinerea or Colletotrichum capsici (22).

In a preliminary test, we evaluated the activity of azoxystrobin with or without addition of SHAM and the effect of the two most often used solvents, methanol or dimethyl sulfoxide (DMSO) $(0.1 \%)$, on the growth of Italian strains of $M$. oryzae. Strains were grown on MEA medium supplemented with increasing concentrations of azoxystrobin $\left(0,0.001,0.01,0.1,1,10\right.$, and $\left.100 \mathrm{mg} \mathrm{liter}^{-1}\right)$ supplemented or not with SHAM (150 mg liter ${ }^{-1}$ ). The mycelium growth was measured after 7 days of incubation.

DNA isolation and sequencing of the cytochrome $b$ gene. DNA of 32 strains of the 2011 population, including 12 controls and 20 strains with reduced sensitivity to azoxystrobin, was extracted from 7-day-old mycelium by cetyltrimethylammonium bromide-based method (4). The selected strains showed approximately two times faster growth on MEA supplemented with azoxystrobin at $10 \mathrm{mg} \mathrm{liter}^{-1}$, a concentration close to the $\mathrm{ED}_{90}$ value. A 628-bp fragment of the cytochrome $b$ gene was amplified (4) and sequenced. Sequences were compared with the cytochrome $b$ sequence of $M$. oryzae, Guy11 isolate (GenBank accession number AY245424).

Statistical analysis. To calculate the dose-response curves for mycelium growth, nonlinear regression analysis using a three-parameter log-logistic model was employed. The $\mathrm{ED}_{50}$ was estimated by interpolation from the fitted regression curve. The analyses were performed using $\mathrm{R}$ software, version R2.14.0, and the drc package $(31,32)$.

\section{Results}

Mycelium growth on azoxystrobin-supplemented media with or without SHAM. The mycelium growth of M. oryzae on medium supplemented with azoxystrobin and SHAM was inhibited to

Table 1. Characteristics of the Italian populations of Magnaporthe oryzae

\begin{tabular}{llcll}
\hline Population $^{\mathbf{a}}$ & \multicolumn{1}{c}{ Fungicide $^{\mathbf{b}}$} & Isolates $^{\mathbf{c}}$ & \multicolumn{1}{c}{ Origin (province) $^{\text {Rice variety }}$} \\
\hline 1998 & None & 60 & Novara and Pavia & Balilla and Thaibonnet \\
2010 & T or mix T+A, 2-3/year & 60 & Pavia & Vialone nano \\
2011 & T or mix T+A, 2-3/year & 60 & Milano, Novara, Pavia and Vercelli & Mainly Sirio, Vialone nano, and Volano \\
\hline
\end{tabular}

a Year of collection.

${ }^{\mathrm{b}}$ Fungicide and number treatments; $\mathrm{T}=$ tricyclazole and $\mathrm{A}=$ azoxystrobin .

c Number of isolates. 
a higher extent than by azoxystrobin alone (Fig. $1 \mathrm{~A})$. The $\mathrm{ED}_{50}$ value of azoxystrobin was $0.11 \mathrm{mg} \mathrm{liter}^{-1}$, whereas it was reduced approximately four times to $0.026 \mathrm{mg} \mathrm{liter}^{-1}$ after the addition of SHAM. The addition of solvents alone at a concentration of $0.1 \%$ did not affect the growth of the fungus, whereas the addition of SHAM at a concentration of $150 \mathrm{mg} \mathrm{liter}^{-1}$ inhibited mycelium growth by $25 \%$ when dissolved in DMSO and by almost $60 \%$ when methanol was used as solvent (Fig. 1B).

Because it was evident that SHAM alone was able to reduce mycelium growth of $M$. oryzae, which could lead to underestimation of the azoxystrobin $\mathrm{ED}_{50}$, we did not include SHAM in our experiments.

Baseline responses of the $M$. oryzae population nonexposed to tricyclazole and azoxystrobin. $M$. oryzae isolates collected in 1998 represent a population that had not been previously exposed to the two fungicides evaluated in the present study. Therefore, this population was used to determine the baseline responses of the pathogen to azoxystrobin and tricyclazole in terms of mycelium growth. The diameter of the mycelium in response to increasing concentrations of the two fungicides was measured after 7 days and a nonlinear regression model was employed to calculate doseresponse curves (Fig. 2).

The average diameter of $M$. oryzae mycelium on control medium was approximately $4 \mathrm{~cm}$ after 7 days of growth (Table 2). The mycelium growth of all isolates decreased with increasing concentrations of azoxystrobin and tricyclazole but the responses to the two fungicides were different. Whereas $\mathrm{ED}_{50}$ values for azoxystrobin were $0.063 \mathrm{mg} \mathrm{liter}^{-1}$ after 7 days of growth, the values were more than 1,000-times higher in the case of tricyclazole (99.289 $\mathrm{mg} \mathrm{liter}^{-1}$ ).

Responses of the $M$. oryzae populations exposed to tricyclazole and azoxystrobin. The response of the 2010 population, ex-

\section{A Effect of SHAM + azoxystrobin on M. oryzae mycelium growth}

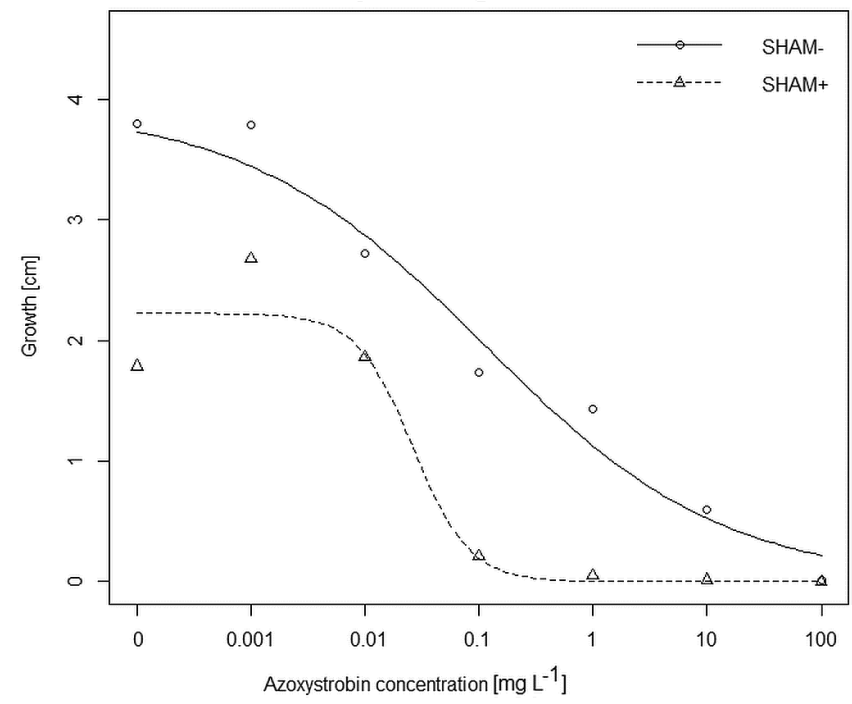

posed to tricyclazole and azoxystrobin, was compared with the baseline to examine a potential shift in pathogen sensitivity. For tricyclazole, both populations exhibited similar growth responses to increasing concentrations of the compound (Fig. 3A), and the

Growth-response curves of $M$. oryzae population nonexposed to fungicides

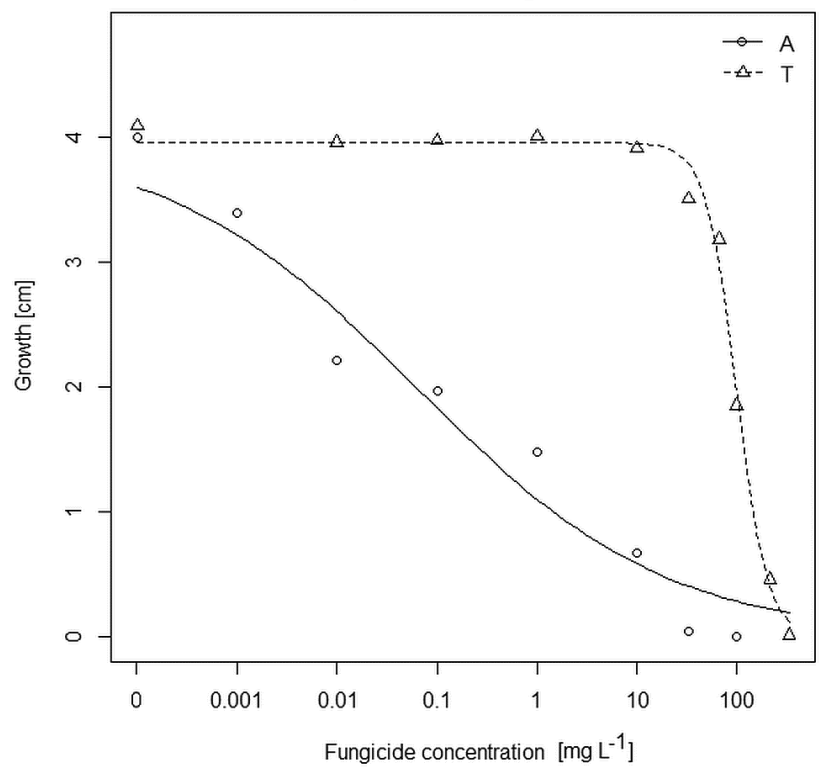

Fig. 2. Mycelium growth dose-response curves of the nonexposed Magnaporthe oryzae population (1998) in response to increasing concentrations of azoxystrobin (A) and tricyclazole (T), measured after 7 days.

Fig. 1. Effect of azoxystrobin, salicylhydroxamic acid (SHAM), and solvents on the mycelium growth of Magnaporthe oryzae. A, Mycelium growth dose-response curves of M. oryzae strains in response to increasing concentrations of azoxystrobin in the absence (SHAM-) or presence (SHAM+) of SHAM (150 mg liter ${ }^{-1}$ dissolved in $0.1 \%$ methanol). B, Effects of different solvents with or without SHAM on the mycelium growth of $M$. oryzae strains in the absence of azoxystrobin. $D=$ dimethyl sulfoxide (DMSO) $0.1 \%$; D+S $=$ DMSO $0.1 \%$ + SHAM at $150 \mathrm{mg} \mathrm{liter}^{-1} ; \mathrm{M}=$ methanol $0.1 \% ; \mathrm{M}+\mathrm{S}=$ methanol $0.1 \%$ + SHAM at $150 \mathrm{mg} \mathrm{liter}^{-1}$.

Table 2. Parameters of the log-logistic regression models for the mycelium growth of the nonexposed population of Magnaporthe oryzae

\begin{tabular}{|c|c|c|c|}
\hline \multirow[b]{2}{*}{ Fungicide } & \multicolumn{3}{|c|}{ Parameter } \\
\hline & b (Slope) & d (Upper limit [cm]) & e $\left(\mathrm{ED}_{50}\left[\mathrm{mg} \mathrm{liter}{ }^{-1}\right]\right)^{\mathrm{b}}$ \\
\hline Tricyclazole & $2.8418(2.7358-2.9478)$ & $3.9515(3.9335-3.9695)$ & $99.289(98.075-100.503)$ \\
\hline Azoxystrobin & $0.3462(0.3353-0.3540)$ & $3.9807(3.9477-4.0137)$ & $0.0630(0.0571-0.0689)$ \\
\hline
\end{tabular}

a The predicted value of individual parameters with the $95 \%$ confidence interval shown in parentheses.

${ }^{\mathrm{b}} \mathrm{ED}_{50}=$ concentration of fungicide causing $50 \%$ growth inhibition. 
parameters of corresponding nonlinear regression models were comparable (Table 3). Moreover, the individual strains were distributed equally based on their $\mathrm{ED}_{50}$ values (Fig. 3B). Also, for azoxystrobin, the curves of both populations were comparable, showing a typical sigmoid shape, where mycelium growth decreased with increasing concentrations of the fungicide (Fig. 4A). The calculated $\mathrm{ED}_{50}$ values were alike for both populations, 0.063 mg liter ${ }^{-1}$ for the nonexposed population and $0.062 \mathrm{mg} \mathrm{liter}^{-1}$ for the exposed population (Table 3). Similarly, the distribution of individual strains based on their $\mathrm{ED}_{50}$ values was 0.01 to $0.25 \mathrm{mg}$ liter $^{-1}$ in both populations (Fig. 4B).

Finally, the responses of the experimentally selected population to both fungicides were studied. For tricyclazole, growth-response curves and the distribution of strains did not reveal any differences between the control and experimentally selected subpopulations (Fig. 5; Table 3). In both cases, the mean $\mathrm{ED}_{50}$ values (approximately $78 \mathrm{mg} \mathrm{liter}^{-1}$ ) were slightly lower than the baseline. For azoxystrobin, the $\mathrm{ED}_{50}$ of the experimentally selected subpopulation was $0.095 \mathrm{mg} \mathrm{liter}^{-1}$, approximately two times higher than that of the control group $\left(0.054 \mathrm{mg} \mathrm{liter}^{-1}\right)$ and the dose-response curves of the two subpopulations were shifted (Fig. 6A; Table 3). Moreover, when the distribution of strains based on their $\mathrm{ED}_{50}$ was analyzed, slight differences were observed, although not statistically significant (Fig. 6B).
The cytochrome $b$ sequences of neither the control group nor the strains less sensitive to azoxystrobin showed any point mutation and were identical to the wild-type cytochrome $b$ sequence of the Guy11 isolate of M. oryzae (data not shown).

\section{Discussion}

In this study, we determined the baseline responses of $M$. oryzae to tricyclazole and azoxystrobin, the two most widely used fungicides for rice blast management in Italy. Moreover, the sensitivity of populations obtained from rice fields repeatedly treated with these fungicides was compared with baselines, to determine the potential adaptation of the pathogen and to detect possible tricyclazole- or azoxystrobin-resistant isolates. To our knowledge, this is the first study describing and comparing responses of the rice blast pathogen to tricyclazole and azoxystrobin in terms of mycelium growth.

The nonexposed population, collected in 1998, showed much higher sensitivity to azoxystrobin than to tricyclazole based on its mycelium growth $\left(\mathrm{ED}_{50}=0.063 \mathrm{mg} \mathrm{liter}^{-1}\right.$ for azoxystrobin, $\mathrm{ED}_{50}$ $=99.289 \mathrm{mg} \mathrm{liter}^{-1}$ for tricyclazole), which is in accordance with our previous study (25). This different sensitivity of $M$. oryzae mycelium to the two fungicides can be explained by their diverse modes of action. Whereas azoxystrobin acts on mitochondrial respiration, which influences germination, mycelium growth, and

\section{A Growth-response curves of $M$. oryzae to tricyclazole}

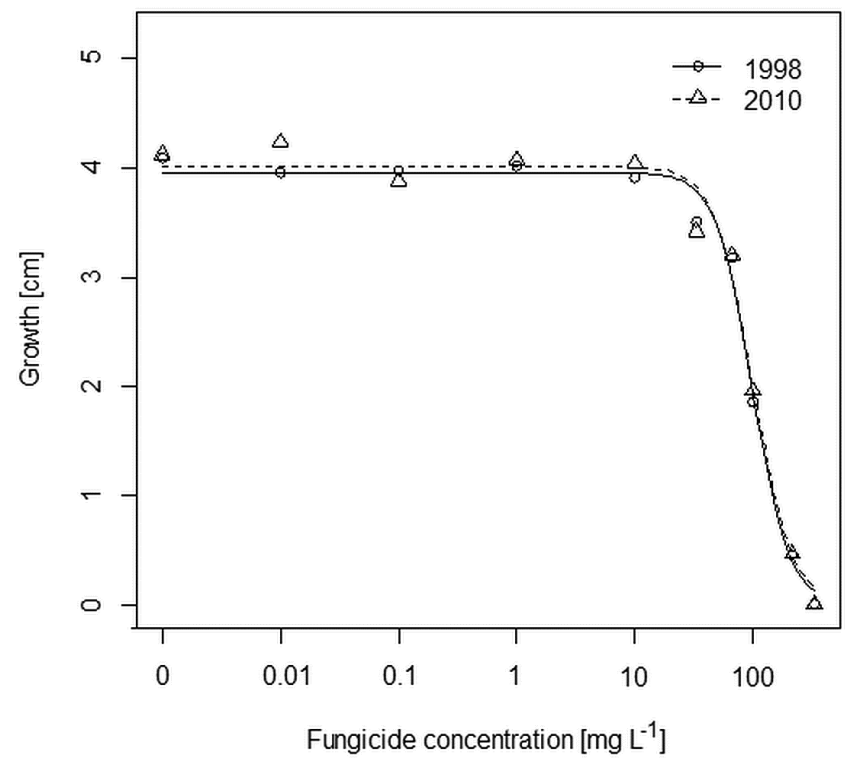

B Distribution of strains based on $\mathrm{ED}_{50}$

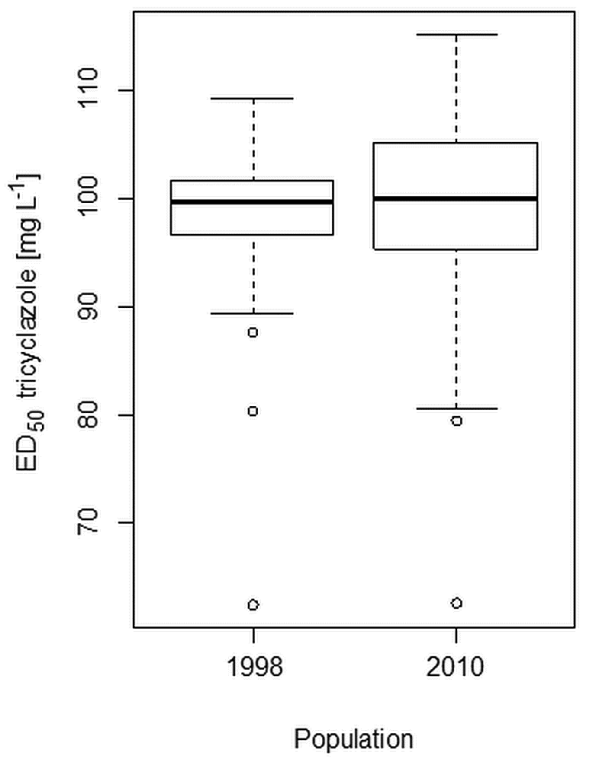

Fig. 3. A, Mycelium growth dose-response curves and B, strain distributions of the nonexposed population (1998) and an exposed population (2010) of Magnaporthe oryzae to tricyclazole, measured after 7 days of growth. $\mathrm{ED}_{50}=$ concentration of fungicide causing $50 \%$ growth inhibition.

Table 3. Parameters of the log-logistic regression models of individual Magnaporthe oryzae populations to azoxystrobin and tricyclazole, measured after 7 days of the mycelium growth ${ }^{\mathrm{a}}$

\begin{tabular}{|c|c|c|c|}
\hline \multirow[b]{2}{*}{ Fungicide, population } & \multicolumn{3}{|c|}{ Parameter } \\
\hline & b (Slope) & d (Upper limit [cm]) & e $\left(\mathbf{E D}_{50}\left[\mathrm{mg} \mathrm{liter}^{-1}\right]\right)^{\mathrm{b}}$ \\
\hline \multicolumn{4}{|l|}{ Tricyclazole } \\
\hline 1998 & $2.842(2.736-2.958)$ & $3.951(3.932-3.971)$ & $99.288(97.953-100.623)$ \\
\hline 2010 & $2.683(2.579-2.786)$ & $4.007(3.987-4.028)$ & $100.34(98.921-101.750)$ \\
\hline 2011T-control & $2.280(2.173-2.388)$ & $4.046(4.013-4.079)$ & $78.568(76.703-80.432)$ \\
\hline 2011T-selected & $2.251(2.145-2.358)$ & $4.075(4.042-4.108)$ & $78.125(76.243-80.007)$ \\
\hline \multicolumn{4}{|l|}{ Azoxystrobin } \\
\hline 1998 & $0.346(0.335-0.354)$ & $3.981(3.948-4.014)$ & $0.0630(0.057-0.069)$ \\
\hline 2010 & $0.415(0.430-0.453)$ & $4.285(4.244-4.327)$ & $0.0619(0.056-0.068)$ \\
\hline 2011A-control & $0.515(0.488-0.541)$ & $4.150(4.072-4.227)$ & $0.0549(0.047-0.063)$ \\
\hline 2011A-selected & $0.474(0.459-0.489)$ & $4.283(4.230-4.336)$ & $0.0957(0.086-0.106)$ \\
\hline
\end{tabular}

${ }^{a}$ The predicted values of individual parameters with the $95 \%$ confidence interval shown in parentheses.

${ }^{\mathrm{b}} \mathrm{ED}_{50}=$ concentration of fungicide causing $50 \%$ growth inhibition. 

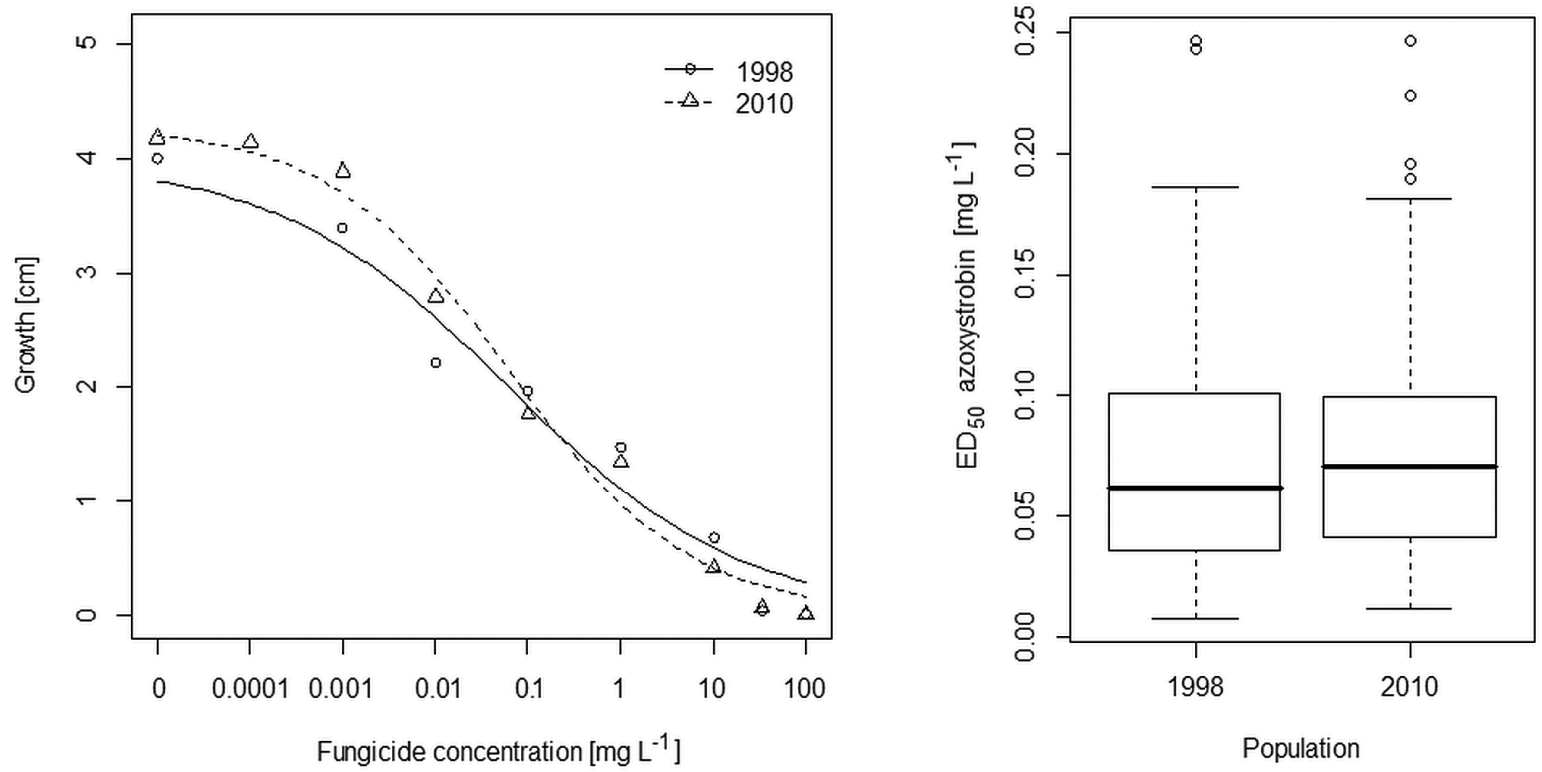

Fig. 4. A, Mycelium growth dose-response curves and B, strain distributions of the nonexposed population (1998) and an exposed population (2010) of Magnaporthe oryzae to azoxystrobin, measured after 7 days of growth. $\mathrm{ED}_{50}=$ concentration of fungicide causing $50 \%$ growth inhibition.

\section{A Growth-response curves of experimentally selected M. oryzae populations to tricyclazole}

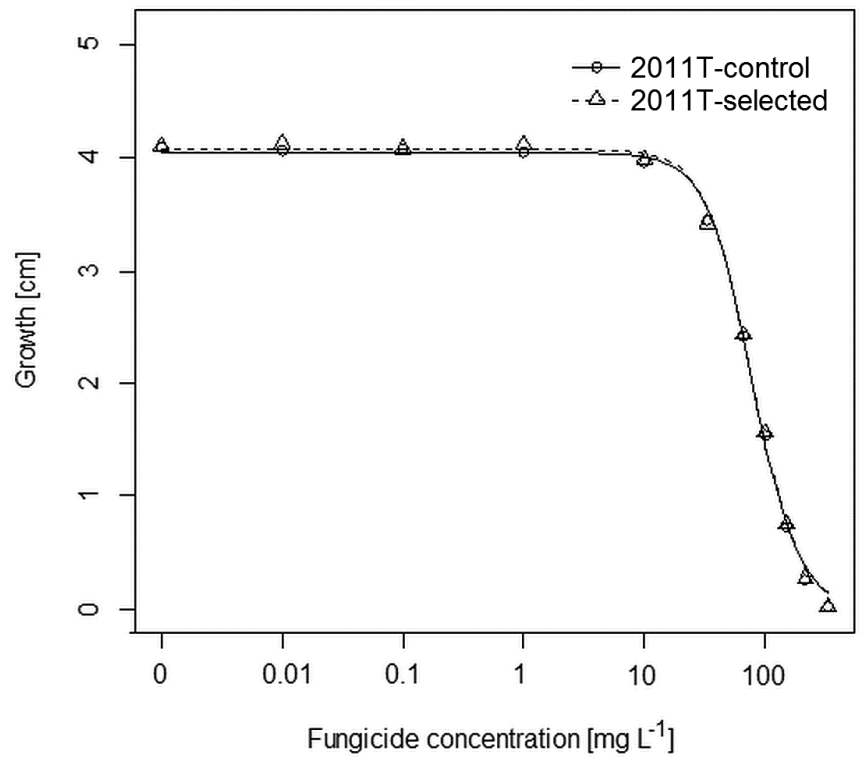

B Distribution of strains based on $\mathrm{ED}_{50}$

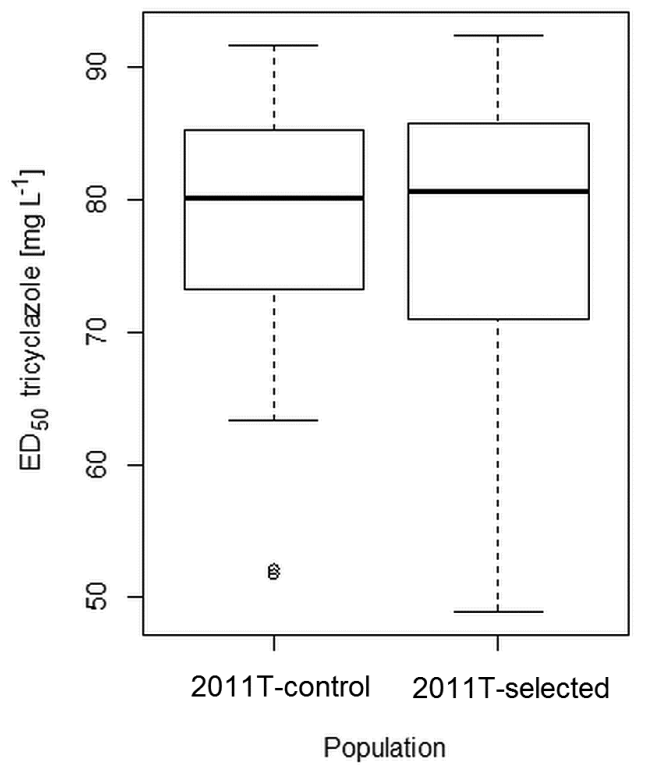

Fig. 5. A, Mycelium growth dose-response curves and B, strain distributions of the experimentally selected populations of Magnaporthe oryzae to tricyclazole, measured after 7 days of growth. $\mathrm{ED}_{50}=$ concentration of fungicide causing $50 \%$ growth inhibition.

sporulation of the pathogen $(8,22)$, tricyclazole specifically inhibits melanin biosynthesis, which does not interfere with viability directly but hampers pathogen penetration into the host and reduces sporulation and virulence $(25,37,38,41)$. Strains of the nonexposed population showed much higher variability in response to azoxystrobin (approximately 30 -fold range of their $\mathrm{ED}_{50}$ values) than to tricyclazole (1.75-fold range of their $\mathrm{ED}_{50}$ values). Azoxystrobin inhibits the mitochondrial respiration which, in $M$. oryzae, can be compensated for to some extent by AOX expression $(3,29)$. It is possible that the variability in AOX expression may account for the higher variability of strains in response to azoxystrobin.

The AOX inhibitor, SHAM, is often used in experiments evaluating activity of QoIs on germination, mycelium growth, or sporula- tion of diverse pathogens in vitro $(3,5,22,30)$. The use of SHAM in vitro is based on the assumption that AOX is not active in planta (5). However, this model was challenged in a study where, by the use of AOX mutants of $M$. oryzae, it was shown that alternative oxidation pathway was active also in planta, therefore questioning the use of SHAM in vitro to suppress AOX in M. oryzae (3). For this reason, and because we showed the inhibitory effect of SHAM alone on mycelium growth of $M$. oryzae, the compound was not included in our study.

The population of $M$. oryzae collected from rice fields repeatedly treated with the two fungicides over a 12-year period did not demonstrate reduced sensitivity to either azoxystrobin or tricyclazole. No significant differences were observed between the $\mathrm{ED}_{50}$ distribution of the baseline and the exposed strains, although the 
A Growth-response curves of experimentally selected M. oryzae populations to azoxystrobin

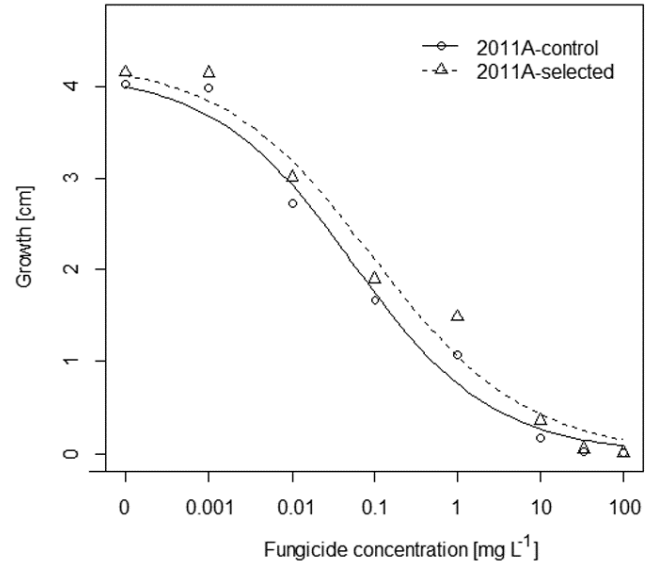

B Distribution of strains based on ED 50

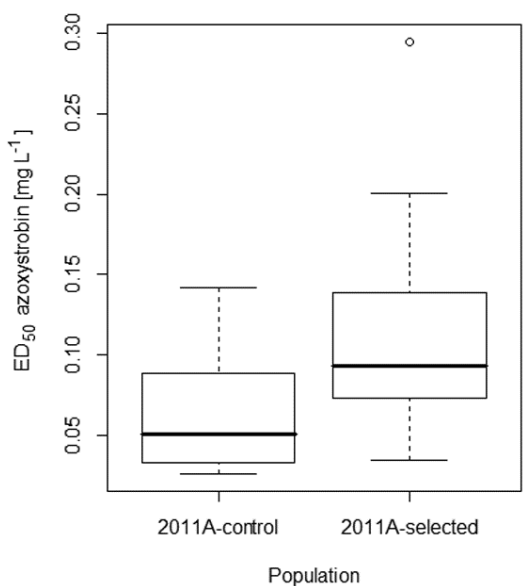

Fig. 6. A, Mycelium growth dose-response curves and B, strain distributions of the experimentally selected populations of Magnaporthe oryzae to azoxystrobin, measured after 7 days of growth. $\mathrm{ED}_{50}=$ concentration of fungicide causing $50 \%$ growth inhibition.

variability of $\mathrm{ED}_{50}$ values was much higher for azoxystrobin than for tricyclazole.

Recently, M. oryzae strains resistant to azoxystrobin have been detected in the field in Japan $(1,18,43)$, and decreased sensitivity was reported also in $M$. oryzae from perennial ryegrass in the United States, as a consequence of the mutation in the cytochrome $b$ gene $(24,40)$. On the other hand, attempts to obtain stable tricyclazole-resistant strains in laboratory were not successful, and strains with slightly decreased tricyclazole sensitivity showed lower fitness, reduced sporulation, and pathogenicity to rice (44). Reduced tricyclazole efficiency to control rice blast in the field was observed in a few provinces in China but the detailed analysis of these isolates did not confirm the presence of tricyclazole-resistant strains (43). In our study, we have not identified any azoxystrobinor tricyclazole-resistant strains even in the experimentally selected population. In fact, the 20 putative azoxystrobin-resistant strains, with an average resistance factor equal to 2 , did not show any mutation at $\mathrm{F} 129$ or $\mathrm{G} 137$ positions in the cytochrome $b$ gene, known to confer resistance factors between 5 and $15(17,24)$.

Our results indicate that, at present, in Italy, the use of azoxystrobin and tricyclazole did not result in selection of resistant strains; therefore, they can be employed in rice blast management. However, it must be emphasized that regular monitoring of the $M$. oryzae population and correct application rates of fungicides in accordance with the Fungicide Resistance Action Committee and manufacturer guidelines, especially in the case of azoxystrobin, are necessary to delay possible selection of azoxystrobin-resistant strains.

\section{Acknowledgments}

This research was supported, in part, by Dow Agrosciences Italia S.r.l. We thank A. Porcile and F. Gennari for their help and assistance with the experiments.

\section{Literature Cited}

1. Araki, Y., Sugihara, M., Sawada, H., Fujimoto, H., and Masuko, M. 2005. Monitoring of the sensitivity of Magnaporthe grisea to Metominostrobin 2001-2003: no emergence of resistant strains and no mutations at codon 143 or 129 of the cytochrome b gene. J. Pestic. Sci. 30:203-208.

2. Astolfi, G. 1828. Congetture sopra la malattia del brusone che infesta il riso, e rimedii che possono prevenirla. In: Tecnologia. Annali universali di agricoltura, economia rurale e domestica; arti e mestieri, vol. Fascicolo 3-4. Bologna, Italy.

3. Avila-Adame, C., and Koller, W. 2002. Disruption of the alternative oxidase gene in Magnaporthe grisea and its impact on host infection. Mol. PlantMicrobe Interact. 15:493-500.

4. Avila-Adame, C., and Koller, W. 2003. Characterization of spontaneous mutants of Magnaporthe grisea expressing stable resistance to the Qo-inhibiting fungicide azoxystrobin. Curr. Genet. 42:332-338.

5. Avila-Adame, C., and Koller, W. 2003. Impact of alternative respiration and target-site mutations on responses of germinating conidia of Magnaporthe grisea to Qo-inhibiting fungicides. Pest Manage. Sci. 59·303-309.

6. Baldacci, E., and Corbetta, G. 1960. "Brusone" in rice during the year 1959 Fertilité 11:23-24

7. Baldacci, E., and Picco, D. 1948. Osservazioni sulle malttie del riso durante gli anni 1946 e 1947. Risocultura 36:73-77.

8. Bartlett, D. W., Clough, J. M., Godwin, J. R., Hall, A. A., Hamer, M., and Parr-Dobrzanski, B. 2002. The strobilurin fungicides. Pest Manage. Sci. 58:649-662.

9. Bell, A. A., and Wheeler, M. H. 1986. Biosynthesis and functions of fungal melanins. Annu. Rev. Phytopathol. 24:411-451.

10. Brent, K. J., and Hollomon, D. W. 2007. Fungicide Resistance: The Assessment of Risk. Fungicide Resistance Action Committee, Aimprint, United Kingdom.

11. Chadha, S., and Gopalakrishna, T. 2006. Detection of Magnaporthe grisea in infested rice seeds using polymerase chain reaction. J. Appl. Microbiol. 100:1147-1153.

12. Cortesi, P. 2011. Il brusone del riso: Danni causati dalle epidemie e ottimizzazione della difesa con triciclazolo. Pages 87-140 in: Il ruolo economico del triciclazolo nella risicoltura italiana. AGRA, Roma.

13. Di Tullio, E., Tabacchi, M., Tamborini, L., and Cortesi, P. 2012. Valutazione economica del ruolo del triciclazolo nella risicoltura italiana. Pages 503-512 in: Atti Giornate Fitopatologiche. Clueb, Bologna, Italy.

14. Faivre-Rampant, O., Bruschi, G., Abbruscato, P., Cavigiolo, S., Picco, A. M., Borgo, L., Lupotto, E., and Piffanelli, P. 2011. Assessment of genetic diversity in Italian rice germplasm related to agronomic traits and blast resistance (Magnaporthe oryzae). Mol. Breed. 27:233-246.

15. Fang, M. Y., Yan, L., Wang, Z., Zhang, D., and Ma, Z. 2009. Sensitivity of Magnaporthe grisea to the sterol demethylation inhibitor fungicide propiconazole. J. Phytopathol. 157:568-572.

16. FAO. 2013. FAOStat online. http://faostat3.fao.org/faostat-gateway/go/to/ download/Q/QC/E

17. Fungicide Resistance Action Committee. 2006. Mutations associated with QoI-resistance (Status 12/2006). www.frac.info

18. Fungicide Resistance Action Committee. 2012. List of pathogens with field resistance towards QoI fungicides (Status 06/12/2012). www.frac.info

19. Guerber, C., and TeBeest, D. O. 2006. Infection of rice seed grown in $\mathrm{Ar}-$ kansas by Pyricularia grisea and transmission to seedlings in the field. Plant Dis. 90:170-176.

20. Inoue, K., Tsurumi, T., Ishii, H., Park, P., and Ikeda, K. 2012. Cytological evaluation of the effect of azoxystrobin and alternative oxidase inhibitors in Botrytis cinerea. FEMS Microbiol. Lett. 326:83-90.

21. Ishii, H. 2006. Impact of fungicide resistance in plant pathogens on crop disease control and agricultural environment. Jpn. Agric. Res. Q. 40:205.

22. Jin, L.-H., Chen, C.-J., Wang, J.-X., Chen, Y., and Zhou, M.-G. 2009. Activity of azoxystrobin and SHAM to four phytopathogens. Agric. Sci. China 8:835-842.

23. Kaku, K., Takagaki, M., Shimizu, T., and Nagayama, K. 2003. Diagnosis of dehydratase inhibitors in melanin biosynthesis inhibitor (MBI-D) resistance by primer-introduced restriction enzyme analysis in scytalone dehydratase gene of Magnaporthe grisea. Pest Manage. Sci. 59:843-846.

24. Kim, Y.-S., Dixon, E. D., Vincelli, P., and Farman, M. L. 2003. Field resistance to strobilurin $(\mathrm{Q}(\mathrm{o}) \mathrm{I})$ fungicides in Pyricularia grisea caused by mutations in the mitochondrial cytochrome b gene. Phytopathology 93:891-900.

25. Kunova, A., Pizzatti, C., and Cortesi, P. 2013. Impact of tricyclazole and azoxystrobin on growth, sporulation and secondary infection of the rice blast fungus, Magnaporthe oryzae. Pest Manage. Sci. 69:278-284.

26. Kurahashi, Y. 2001. Melanin biosynthesis inhibitors (MBIs) for control of 
rice blast. Pestic. Outlook 12:32-35.

27. Liu, J., Wang, X., Mitchell, T., Hu, Y., Liu, X., Dai, L., and Wang, G. L. 2010. Recent progress and understanding of the molecular mechanisms of the rice-Magnaporthe oryzae interaction. Mol. Plant Pathol. 11:419-427.

28. Long, D. H., Correll , J. C., Lee, F. N., and TeBeest, D. O. 2001. Rice blast epidemics initiated by infested rice grain on the soil surface. Plant Dis. 85:612-616.

29. Ma, B., Uddin, W., and Olaya, G. 2009. Baseline and non-baseline sensitivity of Magnaporthe oryzae isolates from perennial ryegrass to azoxystrobin in the northeastern United States. Can. J. Plant Pathol. 31:57-64.

30. Paplomatas, E. J., Pappas, A. C., and Syranidou, E. 2005. Molecular characterization and biological response to respiration inhibitors of Pyricularia isolates from ctenanthe and rice plants. Pest Manage. Sci. 61:691-698.

31. R Development Core Team. 2011. R: A Language and Environment for Statistical Computing. R Foundation for Statistical Computing, Vienna.

32. Ritz, C., and Streibig, J. C. 2005. Bioassay analysis using R. J. Stat. Softw. $12: 1-22$.

33. Sawada, H., Sugihara, M., Takagaki, M., and Nagayama, K. 2004. Monitoring and characterization of Magnaporthe grisea isolates with decreased sensitivity to scytalone dehydratase inhibitors. Pest Manage. Sci. 60:777-785.

34. Skamnioti, P., and Gurr, S. J. 2009. Against the grain: Safeguarding rice from rice blast disease. Trends Biotechnol. 27:141-150.

35. Suzuki, F., Yamaguchi, J., and Koba, A. 2010. Changes in fungicide resistance frequency and population structure of Pyricularia oryzae after discontinuance of MBI-D fungicides. Plant Dis. 94:329-334.

36. Takagaki, M., Kaku, K., Watanabe, S., Kawai, K., Shimizu, T., Sawada, H., Kumakura, K., and Nagayama, K. 2004. Mechanism of resistance to carpro- pamid in Magnaporthe grisea. Pest Manage. Sci. 60:921-926.

37. Thompson, J. E., Basarab, G. S., Andersson, A., Lindqvist, Y., and Jordan, D. B. 1997. Trihydroxynaphthalene reductase from Magnaporthe grisea: Realization of an active center inhibitor and elucidation of the kinetic mechanism. Biochemistry-US 36:1852-1860.

38. Thompson, J. E., Fahnestock, S., Farrall, L., Liao, D.-I., Valent, B., and Jordan, D. B. 2000. The second naphthol reductase of fungal melanin biosynthesis in Magnaporthe grisea. J. Biol. Chem. 275:34867-34872.

39. Uehara, T., Arase1, S., Honda1, Y., Nozu1, M., and Tswimoto, K. 1995. Effect of pyroquilon, an inhibitor of melanin synthesis, on sporulation and secondary infection of Magnaporthe grisea. J. Phytopathol. 143:573-576.

40. Vincelli, P., and Dixon, E. 2002. Resistance to Q(o)I (strobilurin-like) fungicides in isolates of Pyricularia grisea from perennial ryegrass. Plant Dis. 86:235-240.

41. Woloshuk, C. P., Sisler, H. D., and Vigil, E. L. 1983. Action of the antipenetrant, tricyclazole, on appressoria of Pyricularia oryzae. Physiol. Plant Pathol. 22:245-IN221.

42. Yamaguchi, J., Kuchiki, F., Hirayae, K., and So, K. 2002. Decreased effect of carpropamid for rice blast control in the west north area of Saga Prefecture in 2001. Jpn. J. Phytopathol. 68:261.

43. Zhang, C.-Q., Huang, X., Wang, J.-X., and Zhoub, M.-G. 2009. Resistance development in rice blast disease caused by Magnaporthe grisea to tricyclazole. Pestic. Biochem. Physiol. 94:43-47.

44. Zhang, C. Q., Zhu, G. N., Ma, Z. H., and Zhou, M. G. 2006. Isolation, characterization and preliminary genetic analysis of laboratory tricyclazoleresistant mutants of the rice blast fungus, Magnaporthe grisea. J. Phytopathol. 154:392-397. 